\title{
Track loading on Russian Railways under modern maintenance conditions
}

\author{
Victor Kochergin ${ }^{1, *}$, Igor Maksimov ${ }^{1}$, Victor Pevzner ${ }^{1}$, and Evgeniya Polunina ${ }^{1}$ \\ ${ }^{1}$ Joint Stock Company Railway Research Institute, 3rd Mytischinskaya Street, 10, 129626, Russia, \\ Moscow
}

\begin{abstract}
Rail fasteners loading and its influence on the track deformability under modern maintenance conditions with increased cars axle loads is observed. The difference between one- and two-point wheelrail contact loading scheme is shown. The authors present the analysis of domestic and foreign methods of pads bench tests and show the necessity of carrying out tests imitating real (two-point contact) loading of pads. The bench test method for researching fastener loading and pad strain characteristics in a wide range of vertical and lateral loads under two-point contact scheme based on a number of field tests is presented. The results of static tests and following dynamic ones with cycling loading, which were carried out on a two-sleepers bench, are observed. Bench tests carried out by VNIIZHT and the analysis of the cyclic test methods showed the importance of fasteners tests with a real loading simulation making it possible to explain the causes of track gauge widening and decrease of track inclination, which considerably influences track stability and wear of the track and rolling stock.
\end{abstract}

\section{Introduction}

Russian railways are now replacing conventional freight cars with $250-270 \mathrm{kN}$ axle load cars, making up trains with a mass of 12-14 thousand tons. As the strength of modern track design (rails, fasteners, sleepers, ballast) is of no concern, attention should be paid to track deformability [1-2].

Elastic stress-strain performance characteristics of the track in lateral directions are defined, to great extent, by the design and properties of fasteners. Deformations of the pads under loading determine track loading, rail inclination, rail side wear intensity, wheel flange wear, and to a large extent safety of operation.

Deformations and stiffness characteristics of the track are considerably influenced by the type of wheel-rail contact (one- or two-point).

In such circumstances it becomes necessary to check whether current rail fastener tests match real operation conditions.

It is known that there are two types of wheel-rail contact: one- and two-point (Figure 1).

* Corresponding author: kochergin.viktor@vniizht.ru 

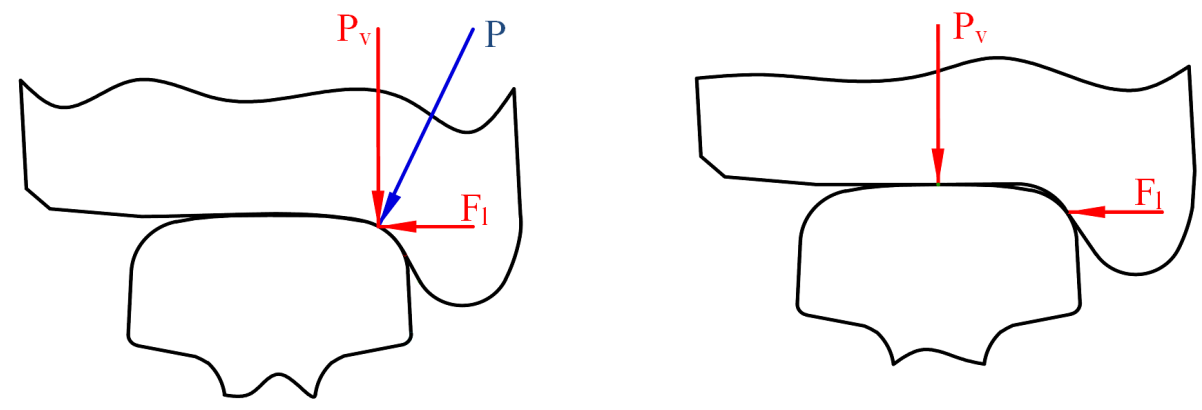

Fig. 1. One-point- (left) and two-point- (right) contact scheme.

Wheel and rail profiles, used on Russian railways since 1970-s, produce two-point contact. This radically changed the loading of rail fasteners, including pads, compared with a one-point contact.

Current Russian test methods (as well as European ones) simulate one-point contact loading [3]. Therefore, the analysis was carried out to evaluate the influence of changing the vertical and lateral loading points according to one- and two-point contact. The difference between these two schemes can be clearly demonstrated by comparing loading of pads on a life testing bench according to Russian authorized test procedures, with loading of pads on the same testing bench but simulating two-point contact.

Traditionally pad loading in a one-point contact scheme is a single force of $115 \mathrm{kN}$ applied at an angle of $\sim 27^{\circ}$ to the rail web axis. This force has a vertical component of $\mathrm{P}_{\mathrm{v}}=102,5 \mathrm{kN}$ and a lateral component of $\mathrm{F}_{1}=52,2 \mathrm{kN}$. Such loading is assumed to be common for all types of fasteners irrespective of their design. This assumption is not quite correct, as shown below. A cyclic loading scheme for life tests is presented on Figure 2a. This loading leads to compression of a pad, and prevents the appearance of a shear strain, caused by lateral component of force.

a)

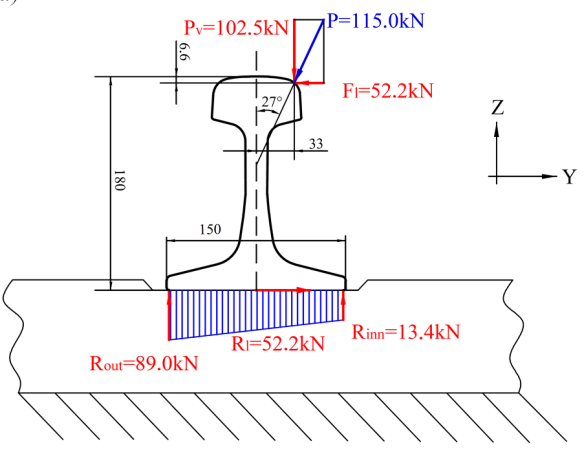

b)

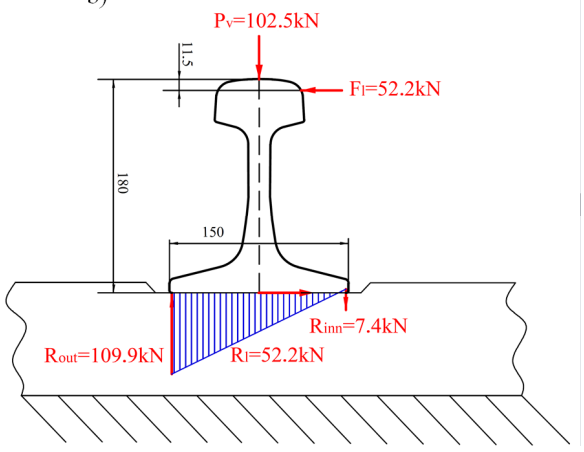

Fig. 2. Fasteners loading scheme. a) one-point contact; b) two-point contact.

For comparison, Figure $2 \mathrm{~b}$ shows the same loads applied under a two-point contact scheme. In this case an opposite moment of a vertical component of force that partly balances a tilting moment of a lateral component of force is absent. This leads to a considerable increase of reaction on the outer side of a rail base and the appearance of an opposite force on its inner side. Deformations and the amount of pad strain change considerably. 


\section{Research}

Field tests on active conventional line were carried out in winter and summer conditions in order to work out a method for the determination of loads and loading schemes for different types of fasteners and pads.

Results made it possible to determine the load distribution along a rail and the quantity of sleepers loaded by the crossing wheel. This validated a bench test method for researching fastener loading and pad strain characteristics in a wide range of vertical and lateral loads under two-point contact scheme.

A test bench for studying the loading of fasteners as part of a rail track was also made. The test bench is an 18-sleeper fragment of track laid on a ballast with a standard gravel top layer and sand bottom layer (Figure 3). Rails are mounted with fasteners that are being tested. Vertical and lateral forces are applied separately to the head of each rail. R65 type rails are mounted on concrete sleepers compatible with the type of fasteners.

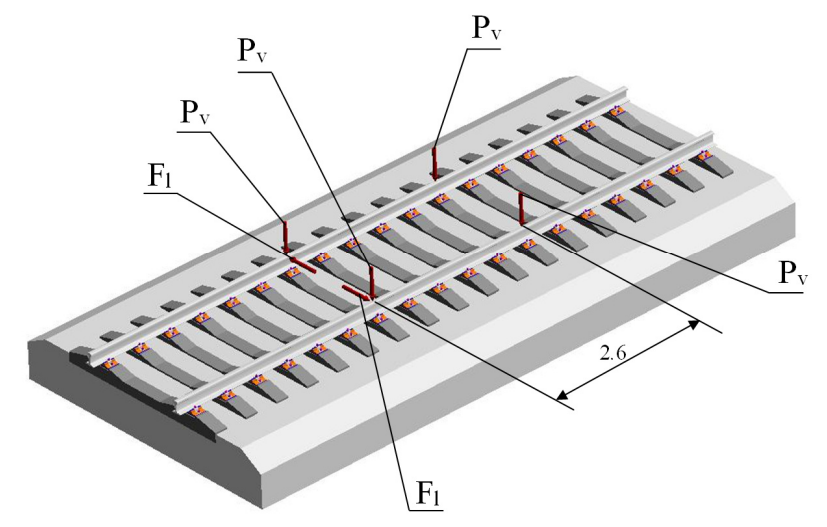

Fig. 3. The model of the 18-sleepers testing bench.

It has been discovered that the most loaded sleeper absorbs about $30 \%$ of the vertical load and $27-38 \%$ of the lateral load depending on the type of fastener used.

It's worth noticing that the quantity of sleepers which are subject to vertical and lateral loading is invariant with applied force magnitudes over a wide range of their variation and depends on fasteners stiffness characteristics including pads, clips, etc.

Static tests were followed by dynamic ones with cyclic loading, which were carried out on a two-sleepers bench, representing a track fragment about $1 \mathrm{~m}$ long.

The test bench consists of two cuts of a rail for each type of fastener laid on concrete sleepers bound with a concrete screed which avoids bending and torsion of sleepers. The model of a test bench for cyclic loading and a loading scheme for KB and ARS fasteners is presented on Figure 4. This test bench makes it possible to simulate the deformations of fasteners' elastic elements obtained from testing on the 18-sleepers test bench.

Vertical and lateral loads were applied to each rail in the symmetry plane between the sleepers. This load application ensures simultaneous uniform loading of four fasteners of the same type. During cyclic tests the fasteners were loaded with pulsing forces with a frequency of $5 \mathrm{~Hz}$. The tests were held indoors at a temperature of $\sim 20^{\circ} \mathrm{C}$. 


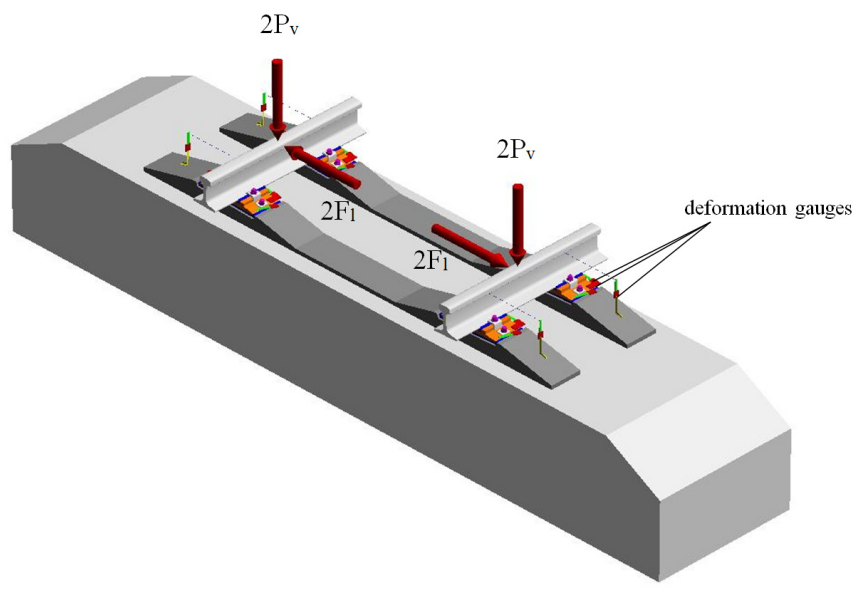

Fig. 4. The model of the testing bench for cyclic loading.

Cyclic tests on the two-sleepers test bench showed that changes in track gauge are caused by lateral displacements within the fasteners and variance of rail inclination due to pad wear.

\section{Conclusion}

Bench tests of the fasteners carried out by VNIIZhT and analysis of the cyclic tests methods (both Russian and other countries) revealed that:

- separate tests of elastic elements of the fasteners must be carried out for each type of fastener and for pads with different stiffness characteristics;

- loads must be specified in standards or determined by real loading on particular lines caused by heaviest types of rolling stock;

- for long-life performance and the operational stability of fasteners, not only tests of elements but tests of fasteners as an assembly with a simulation of real loading are necessary;

- testing fasteners with a real loading simulation makes it possible to explain the causes of track gauge widening and decrease of rail inclination, which considerably influences track stability and wear of the track and rolling stock.

\section{References}

1. T.E. Notteboom, F. Parola, G. Satta, A.A. Pallis, The relationship between port choice and terminal involvement of alliance members in container shipping. J. of Trans. Geog., 64, 158-173 (2017)

2. S. Kaewunruen, C. Chiengson, Railway track inspection and maintenance priorities due to dynamic coupling effects of dipped rails and differential track settlements. Eng. Fail. Anal., 93, 157-171 (2018)

3. L. Le Pen, D. Milne, D. Thompson, W. Powrie, Evaluating railway track support stiffness from trackside measurements in the absence of wheel load data. Canad. Geotech. J. 53(7), 1156-1166 (2016) 